\title{
Stability and Thermo-Physical Properties of Ethylene Glycol Based Nanofluids for Solar Thermal Applications
}

\author{
Raviteja Surakasi ${ }^{1}$, Jaikumar Sagari ${ }^{2}$, Krishna Bharath Vinjamuri², Bhanuteja Sanduru $^{2}$, Srinivas Vadapalli²* \\ ${ }^{1}$ Department of Mechanical Engineering, Lendi Institute of Engineering and Technology, Vizianagaram 535005, India \\ ${ }^{2}$ Department of Mechanical Engineering, GITAM, Rushikonda, Visakhapatnam 530022, India
}

Corresponding Author Email: svadapal@gitam.edu

https://doi.org/10.18280/ijht.390114

Received: 10 March 2020

Accepted: 16 October 2020

\section{Keywords:}

solar thermic fluids, multi-walled carbon nanotubes, ethylene glycol - water mixture, viscosity, thermal conductivity, correlation

\begin{abstract}
This article summarizes research involving the evaluation of the thermo-physical properties of ethylene- glycol-based solar thermic fluids oxidized multi-walled carbon nanotubes. Nanofluids were prepared with Ethylene glycol and water as base fluids in 100:0, 90:10 and 80:20 ratios. Base fluids of three categories were dispersed with surfactant-assisted multi-walled carbon nanotubes (MWCNTs) and oxidized MWCNTs in the weight fractions of $0.125,0.25$, and 0.5 percentages to check the influence of surface modification technique on the thermophysical properties. The variation in zeta potential is studied to examine the dispersion stability during 2 months. Thermal conductivity and dynamic viscosity were measured by hot disk method and Anton paar viscometer, respectively. Significant enhancement of thermal conductivity by 15 to $24 \%$ was observed when the base fluids are dispersed with oxidized MWCNTs. In the case of nanofluids dispersed with surfactant-assisted MWCNTs, the improvement is significantly less compared to oxidized MWCNTs. Nanofluids' dynamic viscosity is found to be higher compared to base fluids in the temperature range of 50 to $70{ }^{\circ} \mathrm{C}$. A comprehensive mathematical equation suitable for all weight fraction of MWCNTs and volume percentages of Ethylene glycol was developed, which can forecast the temperature range. The correlation could fit well with the experimental data in reasonable limits.
\end{abstract}

\section{INTRODUCTION}

Over past decades, numerous studies have shown that nanofluids can be used in multiple fields; For instance, heat exchangers, electronic cooling, tribology, engine cooling systems, and solar thermal systems. Their use could boost the heat transfer capability of industrial equipment. The nanofluid is characterized as a mixture of one or more diverse types of nanomaterials in a base fluid. Currently, several types of nanomaterials are being studied by researchers [1-24] for dispersing in base fluids. Nanomaterials currently employed by researchers have classified as 1) carbonaceous materials with a very high thermal conductivity such as graphene, CNTs, diamond etc. 2) metallic nanoparticles like aluminium (Al), Copper $(\mathrm{Cu})$, gold $(\mathrm{Au})$, iron $(\mathrm{Fe})$, silver $(\mathrm{Ag})$, etc. 3) metal oxides or compounds such as copper oxide $(\mathrm{CuO})$, Alumina $\left(\mathrm{Al}_{2} \mathrm{O}_{3}\right)$, titania $\left(\mathrm{TiO}_{2}\right)$, zinc oxide $(\mathrm{ZnO})$, silicon carbide $(\mathrm{SiC})$, silica $\left(\mathrm{SiO}_{2}\right)$ etc

Ethylene glycol - water mixtures can be used as thermic fluids for solar water heating. These fluids can also be used as residential baseboard heaters, heat exchangers, and industries. Ethylene glycol has the advantage of possessing tunable properties by way of diluting with water, thus varying the thermo-physical properties to suit applications. The thermophysical properties of ethylene - glycol water mixtures for use as thermic fluids are shown in Table 1.

Several studies were conducted to assess carbon nanotubes' effect on the thermophysical properties of nanofluids. All researchers witnessed that with a rise of volume fraction, there is a surge in nanofluid thermal conductivity, density, and viscosity while the specific heat decreased. Also, the thermal conductivity and specific heat improved with the increase of temperature.

Table 1. Properties of mono-ethylene glycol - water mixtures for use as thermic fluids

\begin{tabular}{cccc}
\hline $\begin{array}{c}\text { Thermo- } \\
\text { physical } \\
\text { properties }\end{array}$ & $\begin{array}{c}\text { Mono- } \\
\text { ethylene } \\
\text { glycol-water } \\
(80: 20)\end{array}$ & $\begin{array}{c}\text { Mono- } \\
\text { ethylene } \\
\text { glycol-water } \\
(90: 10)\end{array}$ & $\begin{array}{c}\text { Mono- } \\
\text { ethylene } \\
\text { glycol- } \\
\text { water }(100)\end{array}$ \\
\hline $\begin{array}{c}\text { Freezing } \\
\text { point, }{ }^{\circ} \mathrm{C} \\
\text { Boiling } \\
\text { point, }{ }^{\circ} \mathrm{C}\end{array}$ & -12.22 & -28.88 & -43.33 \\
$\begin{array}{c}\text { Viscosity, cP } \\
\text { (at room }\end{array}$ & 122.22 & 133.4 & 194.44 \\
$\begin{array}{c}\text { temperature } \\
\text { Specific heat, } \\
\text { kJ/kg K } \\
\text { (at room }\end{array}$ & 4.608 & 6.422 & 9.090 \\
temperature) \\
$\begin{array}{c}\text { Thermal } \\
\text { conductivity, } \\
\text { W/m K } \\
\text { (at room }\end{array}$
\end{tabular}


All researchers witnessed that with a rise of volume fraction, there is a surge in nanofluid thermal conductivity, density and viscosity while the specific heat decreased. Also, the thermal conductivity and specific heat improved with increase of temperature. On the contrary, the viscosity and density were observed to have reduced as temperature increases. The major deficiency in the studies of most of the researchers is the surface modification technique and use of surfactant which would result in the formation of copious amount of foam.

\subsection{Present studies}

Most of the researchers did not emphasize the issue of nanofluids' stability, which is the key task of using nanofluids is the low stability of the suspensions. The major deficiency in most of the researchers' studies is the surface modification technique and use of surfactant, which would result in the formation of a copious amount of foam. Surface functionalization of MWNTs utilizing acid treatment produces functional groups over the surface of CNTs improving ethylene glycol's solubility. The novelty of the present work is the evaluation of the stability of prepared nanofluids for two months. A comparison of nanofluids dispersed with surfactant-assisted MWCNTs and oxidized MWCNTs in terms of thermal conductivity enhancement is made. Unlike previous the studies, the present studies are intended for application of EG- Water mixtures as thermic fluids. Hence, the ratio of Ethylene glycol water mixtures is taken as $100 \%$, $90 \%$ and $80 \%$ with the boiling point ranging from 120 to $194^{\circ} \mathrm{C}$. Dynamic viscosity and thermal conductivity is evaluated in the temperature range of 50 to the near boiling point of the EG - water mixtures. Comprehensive correlations were predicted for Dynamic viscosity and thermal conductivity in terms mass fraction of MWCNTs, percentage of water, temperature.

\section{MATERIALS AND METHODS}

\subsection{Materials}

Multi-walled Carbon Nanotubes prepared using CVD process was purchased from $\mathrm{M} / \mathrm{s}$ Cheaptubes Inc., USA. The MWCNTs are highly entangled with a purity of $95 \%$ and are of 30-50 nm diameter \& 3-15 $\mu \mathrm{m}$ length. All other chemicals and surfactant used Cetrimonium Bromide (CTAB) are purchased from M/s Sigma Aldrich are analytical grade.

\subsection{Surface modification of multi-walled carbon nanotubes}

Several studies have established that dispersion and stability are vital features in improving nanofluids' thermophysical properties, particularly for thermal conductivity. The dispersion stability of the nanofluids evaluated the final properties of nanofluids. Pristine multi-walled carbon nanotubes are incredibly hydrophobic and are not dispersible in polar solvents like water, Ethylene glycol, alcohols etc. Due to hydrophobicity, nanotubes clusters would form due to agglomeration and would settle down in the liquid medium resulting in loss of properties. The common practice of the researchers is to use a surfactant to disperse CNTs in base fluids. Surfactants escalate the foaming tendency of fluids resulting in decreased heat transfer rates.

Chen et al. [1] and Hou et al. [3] showed that the pristine carbon nanotubes, when purified, become high-quality carbon nanotubes with open ends. Studies of Rosca et al. [4], Vaisman et al. [5] and Chiang et al. [6], demonstrated that acid treatment is the most appropriate method to purify and create polar groups on the surface of the MWCNTs to make them hydrophilic.

In the present studies, the multi-walled carbon nanotubes were surface modified with two techniques 1) surfactantassisted surface modification and 2) oxidation of MWCNTs to produce carboxyl and carbonyl groups on the surface. In the first method, a surfactant Cetrimonium Bromide (CTAB) and MWCNTs are taken in equal weight ratios and dispersed in solvent methanol using an ultra-sonicator for 10 minutes. The solvent and allowed to evaporate, and the resultant surfactantassisted MWCNTs were recovered. For oxidation of MWCNTs, the nanotubes are refluxed in a mixture of 4 Molar $\mathrm{H}_{2} \mathrm{SO}_{4}$ and 4 Molar $\mathrm{HNO}_{3}$ (3:1 volume ratio) for 3 hours. After reflux, the residue was thoroughly washed with distilled water till seven $\mathrm{pH}$ and dried over-night in an oven at $60^{\circ} \mathrm{C}$.

The processed MWCNTs were characterized using FESEM for structure and Fourier Transform infrared spectroscopy for the occurrence of functional groups. Figures $1 \mathrm{a} \& 1 \mathrm{~b}$ shows the HRSEM image of pristine and oxidized CNTs. From Figure $1 \mathrm{~b}$ shows that the purification process has disentangled the MWCNTs and could open the tips.
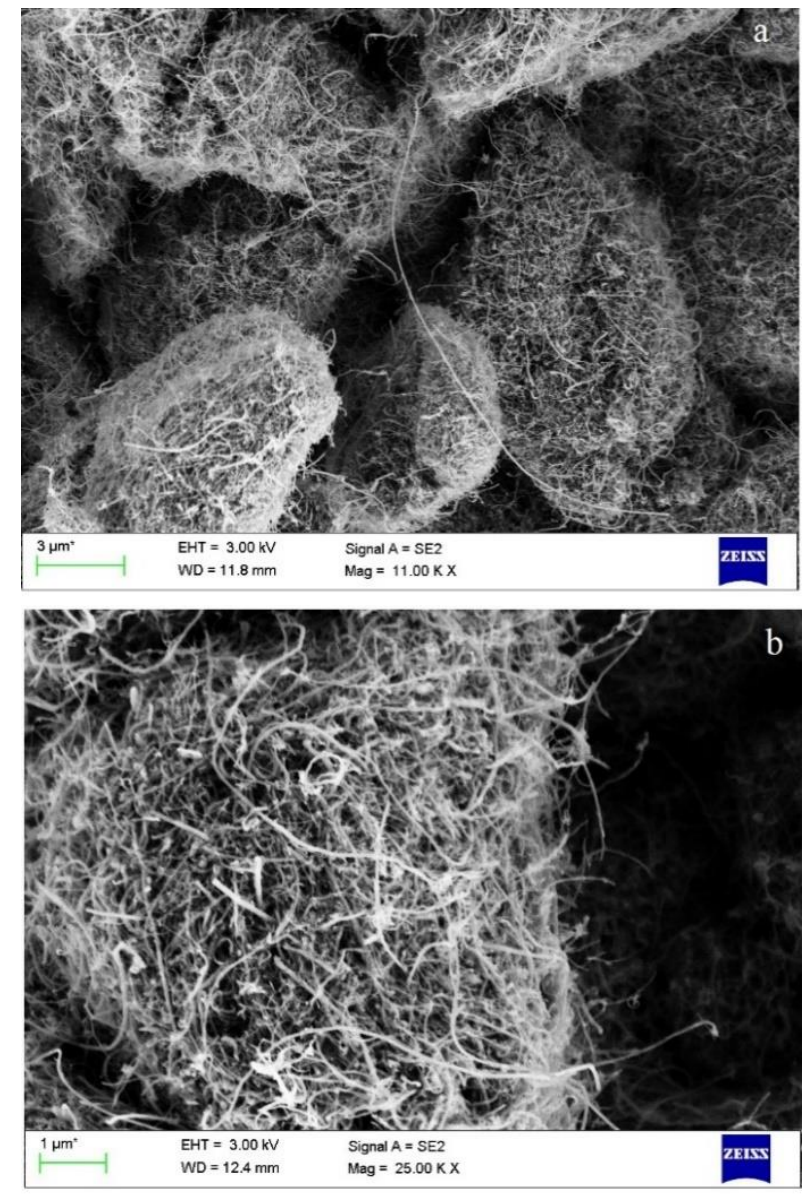

Figure 1. FESEM Image of a) as-received multi-walled carbon nanotubes $b$ ) oxidized multi-walled carbon nanotubes

Figure 2 shows the FTIR Spectrum of pristine MWCNTs and MWCNTs oxidized with acid mixtures. Unlike pristine MWCNTs shown in Figure 2a, the modified MWCNTs in Figure $2 \mathrm{~b}$ display spikes on the spectrum at 1125 and $1740 \mathrm{~cm}^{-}$ 1 , indicating carbonyl and carboxyl groups formed on the MWCNTs. These hydrophilic groups create MWCNTs that 
are highly dispersible in water. High dispersibility is also a precursor for property enhancement compared to unstable nanofluids. The stability measurement by zeta potential is discussed in the next section.

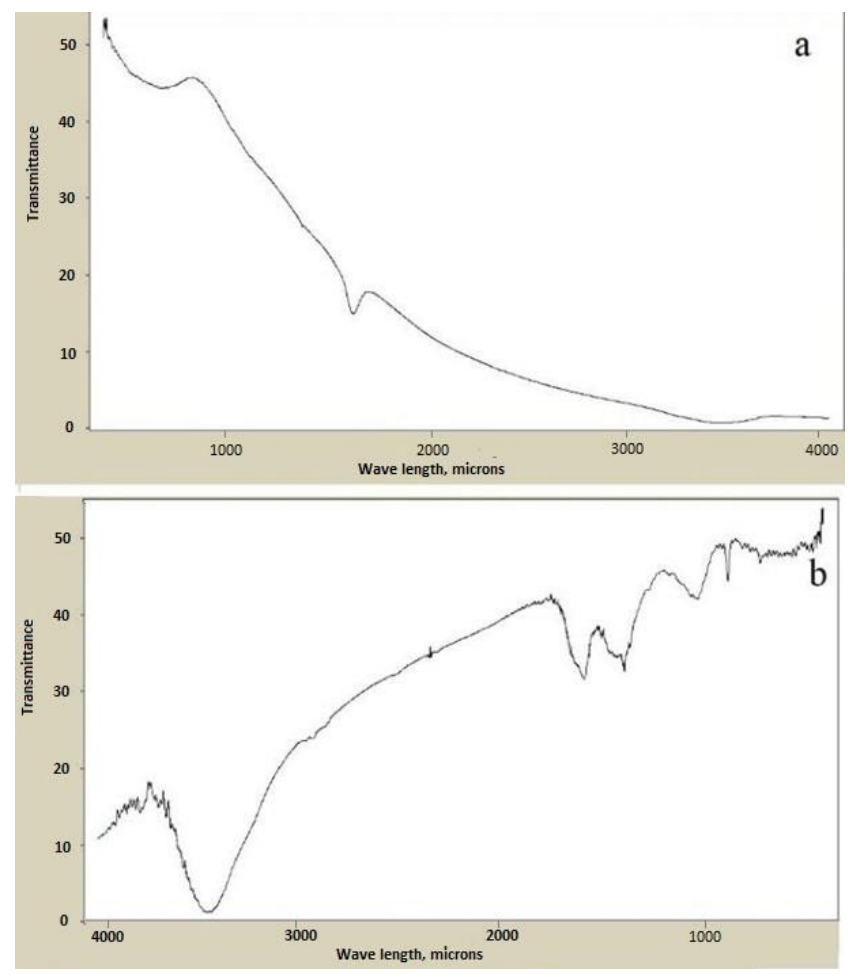

Figure 2. FTIR analysis of a) Pristine MWCNTs b) oxidized MWCNTs

\subsection{Preparation of base fluids and nanofluids}

Table 2. Coolant configuration of base fluids

\begin{tabular}{cc}
\hline S. No & Composition \\
\hline 1 & $100 \%$ Ethylene glycol \\
\hline 2 & $90 \%$ Ethylene glycol $+10 \%$ distilled water \\
\hline 3 & $80 \%$ Ethylene glycol $+20 \%$ distilled water \\
\hline
\end{tabular}

Table 3. Nanofluid configuration

\begin{tabular}{|c|c|}
\hline $\begin{array}{l}\text { S. } \\
\text { No }\end{array}$ & Composition \\
\hline 1 & $\begin{array}{l}100 \% \text { Ethylene glycol+ }(0.125,0.25 \text { and } 0.5 \%) \\
\text { surfactant assisted MWCNTs }\end{array}$ \\
\hline 2 & $\begin{array}{c}90 \% \text { Ethylene glycol }+10 \% \text { distilled water }+(0.125, \\
0.25 \text { and } 0.5 \%) \text { surfactant assisted MWCNTs }\end{array}$ \\
\hline 3 & $\begin{array}{c}80 \% \text { Ethylene glycol }+20 \% \text { distilled water }+(0.125, \\
0.25 \text { and } 0.5 \%) \text { surfactant assisted MWCNTs }\end{array}$ \\
\hline 4 & $\begin{array}{c}100 \% \text { Ethylene glycol+ }(0.125,0.25 \text { and } 0.5 \%) \\
\text { oxidized MWCNTs }\end{array}$ \\
\hline 5 & $\begin{array}{c}90 \% \text { Ethylene glycol }+10 \% \text { distilled water }+(0.125, \\
0.25 \text { and } 0.5 \%) \text { oxidized MWCNTs }\end{array}$ \\
\hline 6 & $\begin{array}{c}80 \% \text { Ethylene glycol }+20 \% \text { distilled water }+(0.125, \\
0.25 \text { and } 0.5 \%) \text { oxidized MWCNTs }\end{array}$ \\
\hline
\end{tabular}

3 types of thermic fluids with the composition of as given below are selected in the current study. The details of base fluids and nanofluids are shown in Tables 2 and 3.

The book size should be in A4 (8.27 inches $\times 11.69$ inches). Do not change the current page settings when you use the template.

The number of pages for the manuscript must be no more than ten, including all the sections. Please make sure that the whole text ends on an even page. Please do not insert page numbers. Please do not use the Headers or the Footers because they are reserved for the technical editing by editors.

\section{STABILITY OF NANOFLUIDS}

Colloidal fluids are assessed for stability through variation of zeta potential of the fluid. The zeta potential specifies the amount of repulsion of charged particles $\left(\mathrm{OH}^{-}, \mathrm{COOH}^{-}\right.$groups existing in MWCNTs and the base liquid). A threshold value of \pm 20 specifiesdeveloping stability of the solution and values exceeding 25 and under -25 indicate good nanofluids' good stability. Ethylene glycol's zeta potential-water mixtures mixed with oxidized MWCNTs is appraised to assess their stability over 60 days.
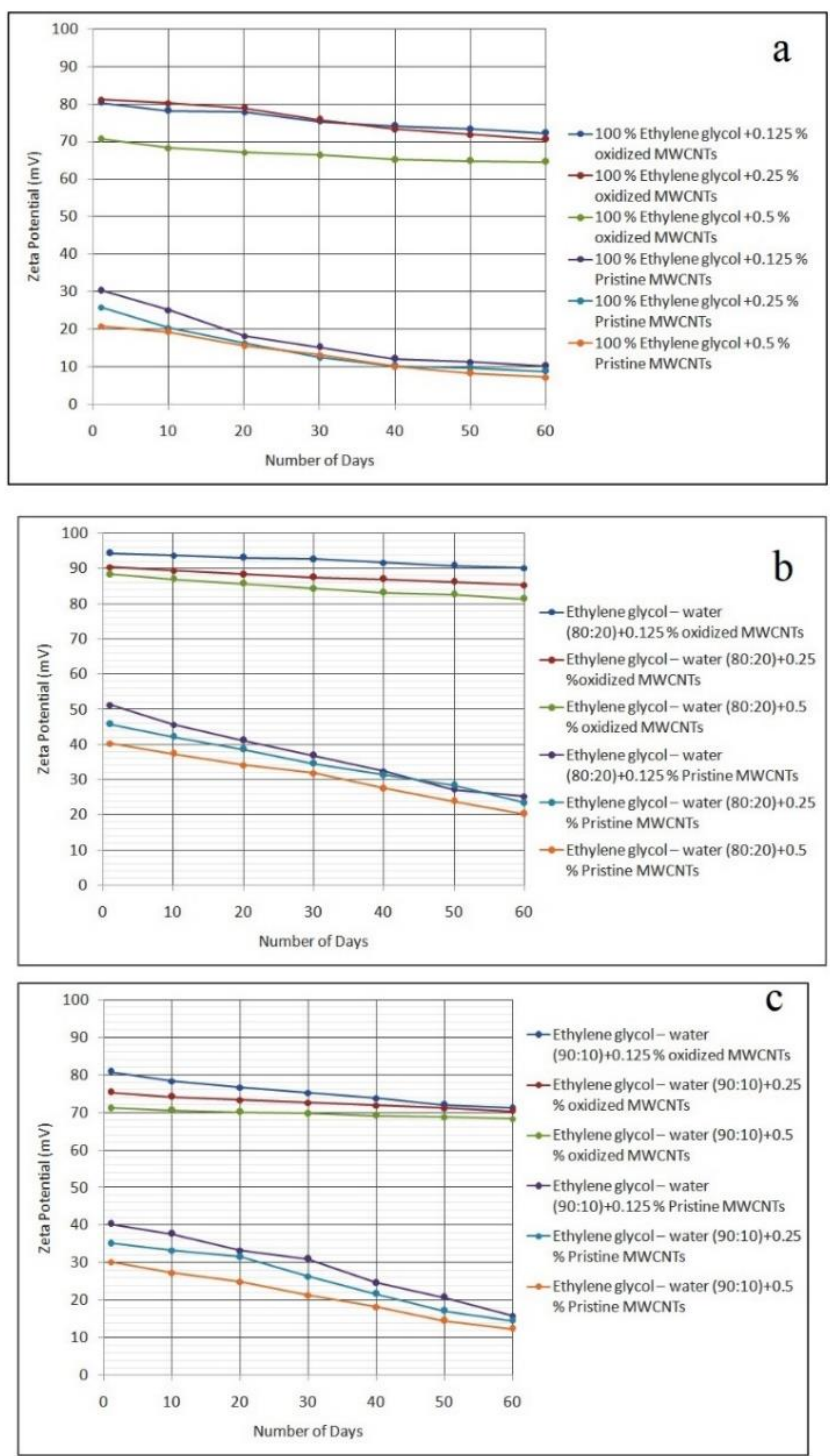

Figure 3. Zeta potential variation of nanofluids with pristine and oxidized MWCNTs for two months

All the nanofluids are tested for stability for two months, and the results are as shown in Figure 3 for the varying composition of ethylene- glycol - water mixtures. The results in Figure 3 conclude that compared to pristine MWCNTs, the surface-modified MWCNTs could remain more stable in the 
coolants. There is a massive difference in the zeta potential from the first day to $60^{\text {th }}$ day in the case of coolants dispersed with pristine MWCNTs. With the dispersion of oxidized MWCNTs, the zeta potential difference over two months is minimal, indicating high stability of the suspensions. This enhanced stability is due to carbonyl and carboxyl groups on the MWCNTs which link with polar groups of Ethylene glycol and water molecules allowing MWCNTs to remain stable in the nanofluids.

Further, Figures $4 \& 5$ show the values of zeta potential of selected coolants. Figure 4 shows the zeta potential of nanofluids dispersed with pristine MWCNTs and it can be seen that the zeta potential is very low on the first day as well as after two months. In Figure 5, which shows the zeta potential variation of nano fluids from the first day to the $60^{\text {th }}$ day, dispersion of oxidized MWCNTs resulted in excellent stability.
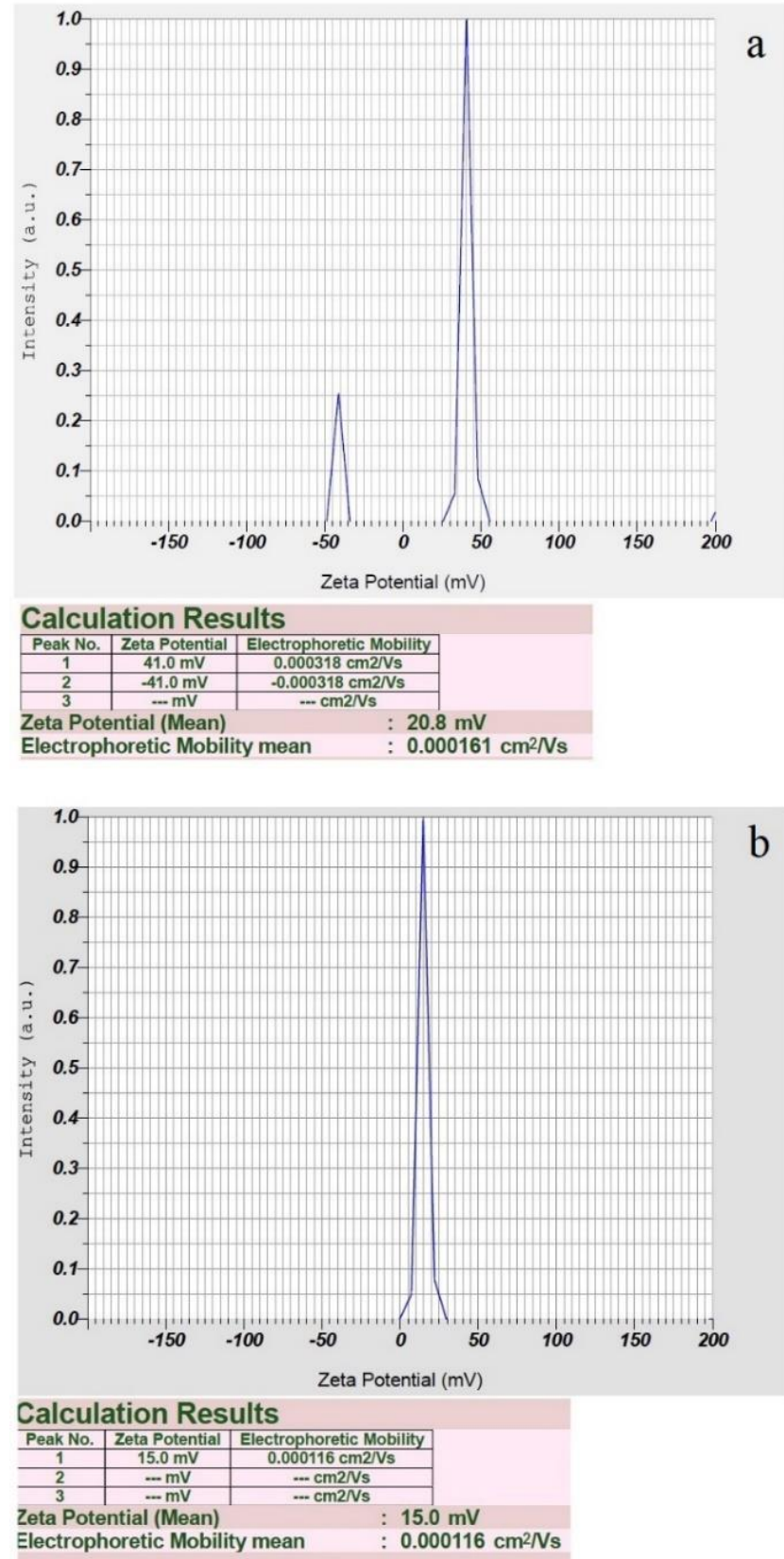

Figure 4. Zeta potential of Ethylene glycol - water mixture (90:20) dispersed with pristine MWCNTs a) first day b) after two months
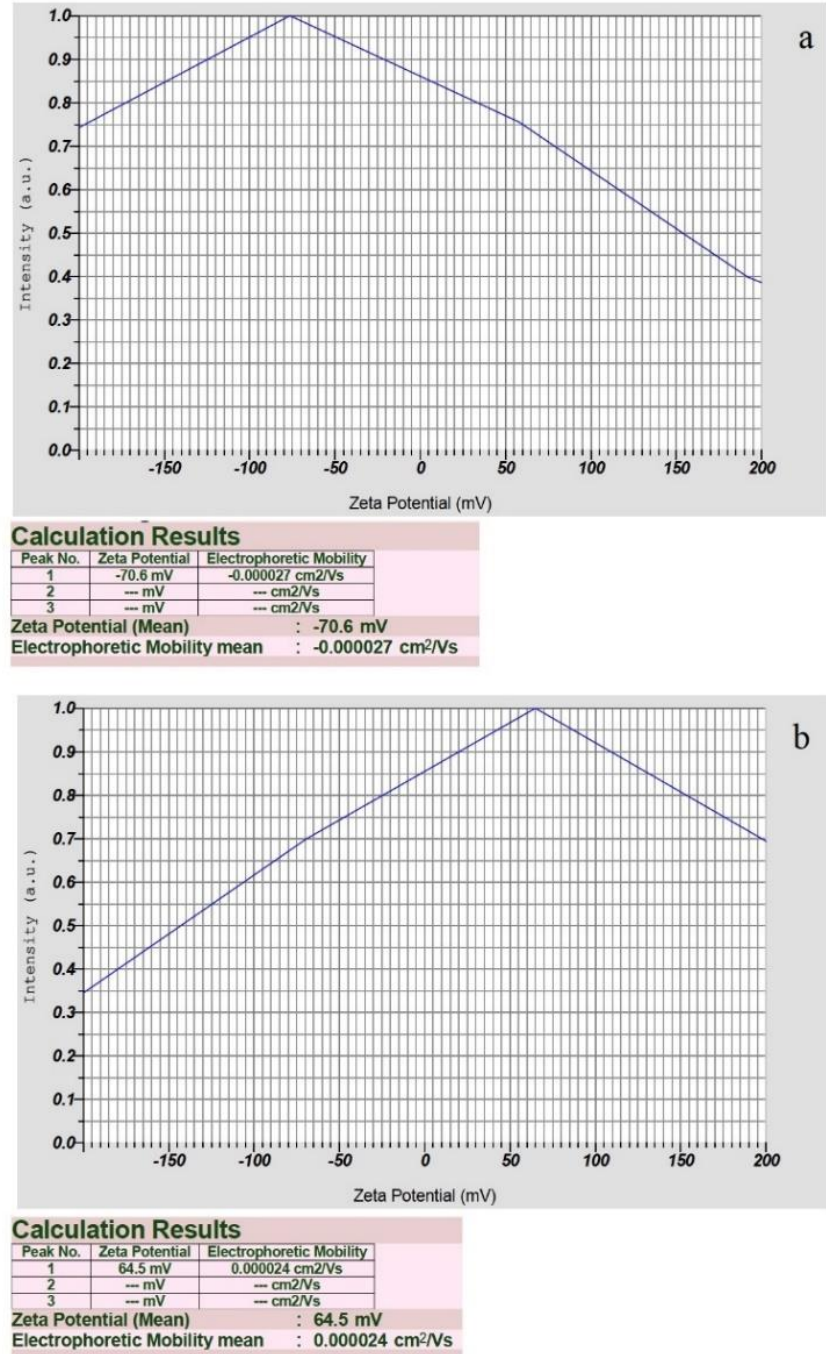

Figure 5. Zeta potential of Ethylene glycol - water mixture (90:20) dispersed with oxidized MWCNTs a) first day b) after two months

\section{THERMO-PHYSICAL PROPERTY EVALUATION}

Evaluation of Thermophysical properties Viz., thermal conductivity, specific heat and dynamic viscosity are very important for assessing thermic fluids' effectiveness. The evaluation of liquids' thermal conductivity is a challenge due to the predominant convective heat transfer in fluids during the measurement. In present studies, thermal conductivity is measured by the Hot Disk method which eliminates errors while measuring liquid thermal conductivity. Kapton sensor 7577 was selected for testing while keeping a short measurement time to reduce convection. Three sets of experiments with different measurement times were conducted on the samples and the average values are reported.

To measure dynamic viscosity ANTON PAAR MCR 302 Rheometer is used for fast and accurate strain control of fluids resulting in very accurate measurements. The samples are tested at different temperatures in three trials and average values are taken. The sample is ensured to be free from air and loaded in the rheometer and the values were noted at steadystate temperature conditions.

All the samples are measured for dynamic viscosity and thermal conductivity in the temperature limits from 50 to near boiling point. 


\section{RESULTS AND DISCUSSIONS}

Figure 6 depicts the variation of thermal conductivity of solar thermic fluid Ethylene glycol - water mixtures with temperature for varying percentage of water and weight fraction of multi-walled carbon nanotubes. It can be found that there is a lessening of thermal conductivity as the temperature increases. For the cases of Ethylene glycol - 10\% Water and Ethylene glycol $-20 \%$ water, there is an initial spike in thermal conductivity followed by a decrease when the temperature increased. The fluids dispersed with MWCNTs performed well in cases of all weight fractions and all percentages of water.
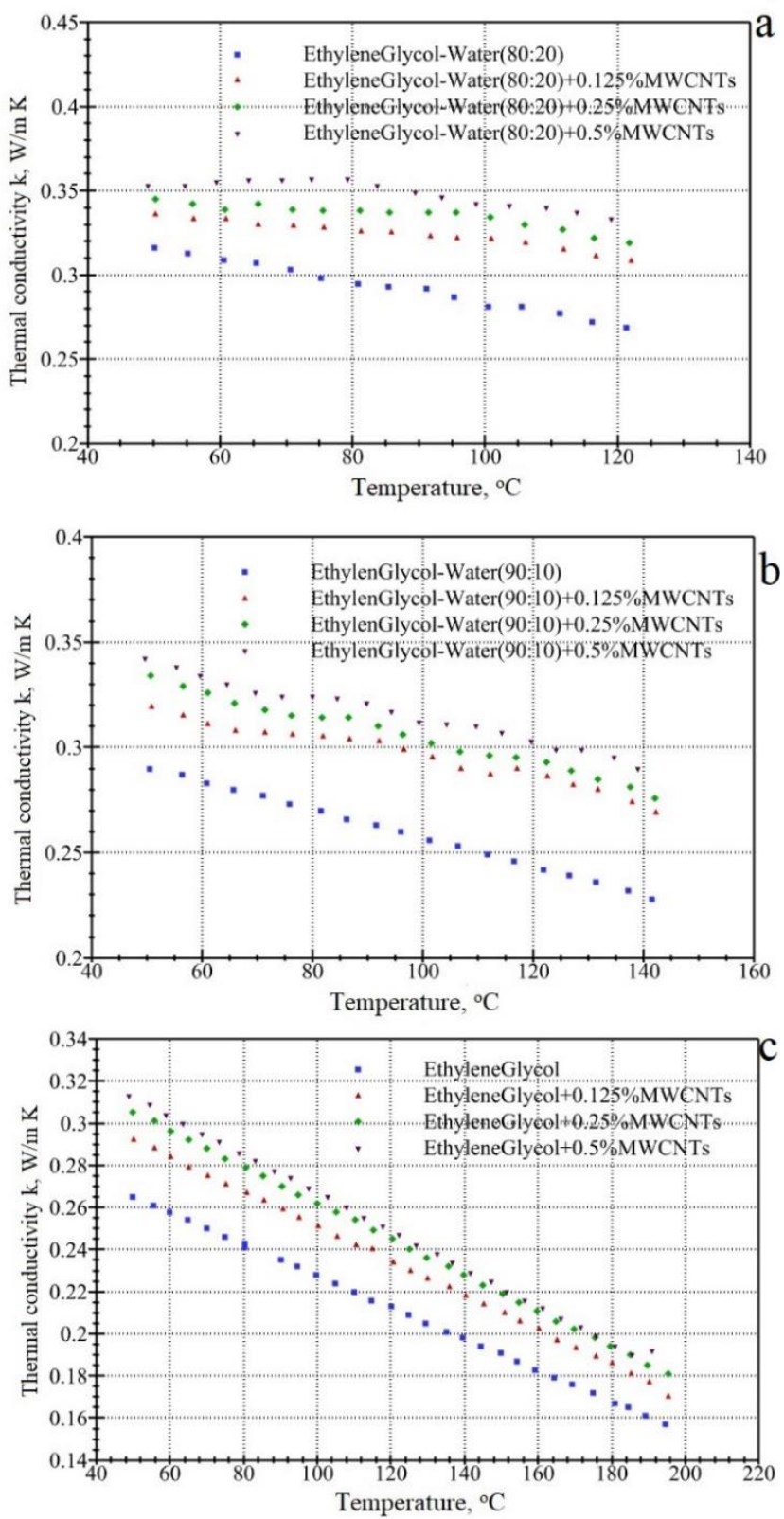

Figure 6. Variation of thermal conductivity with temperature for different Ethylene glycol -water mixture concentrations

The results established that a higher percentage of MWCNTs resulted in higher TC of the nanofluids, as can be perceived from the below figure. The $\mathrm{TC}$ of nanofluids for all percentages of water shown significant improvement compared to corresponding base fluids. Furthermore, it can be established that the $80 \%$ Ethylene glycol- $20 \%$ water combination has shown the highest thermal conductivity increase compared to all other fluids. Meanwhile, pure Ethylene glycol displayed a slightly low enhancement in TC. The influence of temperature on thermal conductivity improvement is also noteworthy. The improvement in TC is more at higher temperatures. The maximum percentage improvement for pure Ethylene glycol, Ethylene glycol - 10\% water mixture and Ethylene glycol $-20 \%$ of water mixtures is $18 \%, 24 \%$ and $26 \%$.
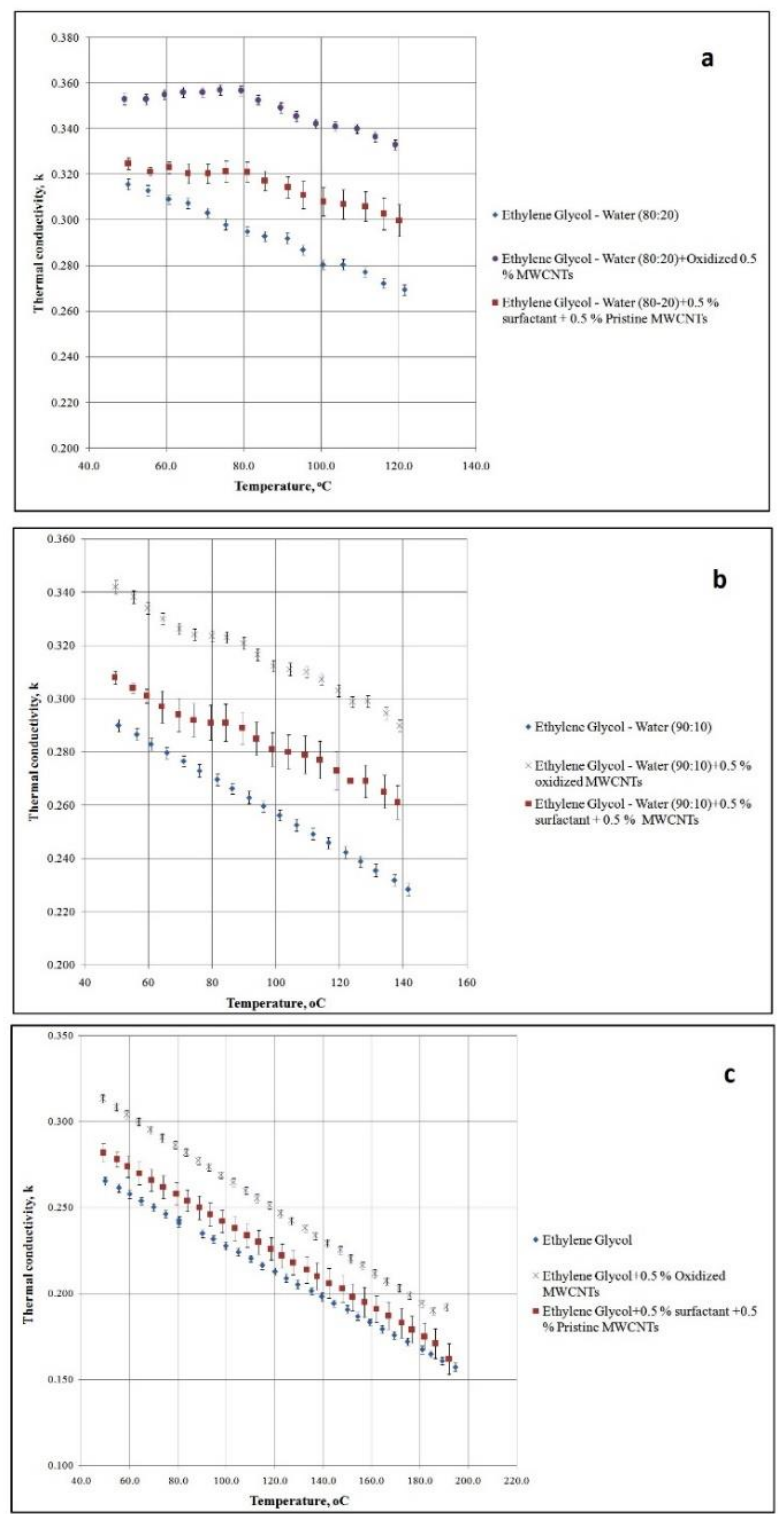

Figure 7. Comparison of thermal conductivity of nanofluids dispersed with surfactant-assisted MWCNTs and oxidized MWCNTs

In Figure 7, a comparison of thermal conductivity enhancement of nanofluids dispersed with surfactant-assisted MWCNTs and oxidized MWCNTs. It is found that surfactantassisted MWCNTs could not much improve the thermal conductivity compared to oxidized MWCNTs at the higher temperature (above $70^{\circ} \mathrm{C}$ ) due to the formation of foaming. Further, the instrumentation error is more during the measurement due to the intervention of bubbles in the foam. In all, taking into account the error in instrumentation, the effect of dispersion of surfactant-assisted MWCNTs is negligible. 
Figure 8 displays the deviation of dynamic viscosity of different nanofluids with temperature. Figure 8a shows the variation of dynamic viscosity for Ethylene glycol - $20 \%$ water mixture in the temperature range of 50 to $125^{\circ} \mathrm{C}$. Figure $8 \mathrm{~b}$ shows the variation of dynamic viscosity for Ethylene glycol $-10 \%$ water mixture range of 50 to $150^{\circ} \mathrm{C}$ and Figure $8 \mathrm{c}$ show the change of dynamic viscosity of pure Ethylene glycol in the temperature limits of 50 to $175^{\circ} \mathrm{C}$. This disparity in maximum temperature is due to the decrease of boiling point with the addition of water. The dynamic viscosity of all fluids shows a decreasing trend with an increase of temperature. A common characteristic with nanofluids is an evident increase in dynamic viscosity with the dispersion of MWCNTs compared to base fluids. The improvement is substantial in nanofluids' dynamic viscosity compared to the equivalent base fluids at lower temperatures.
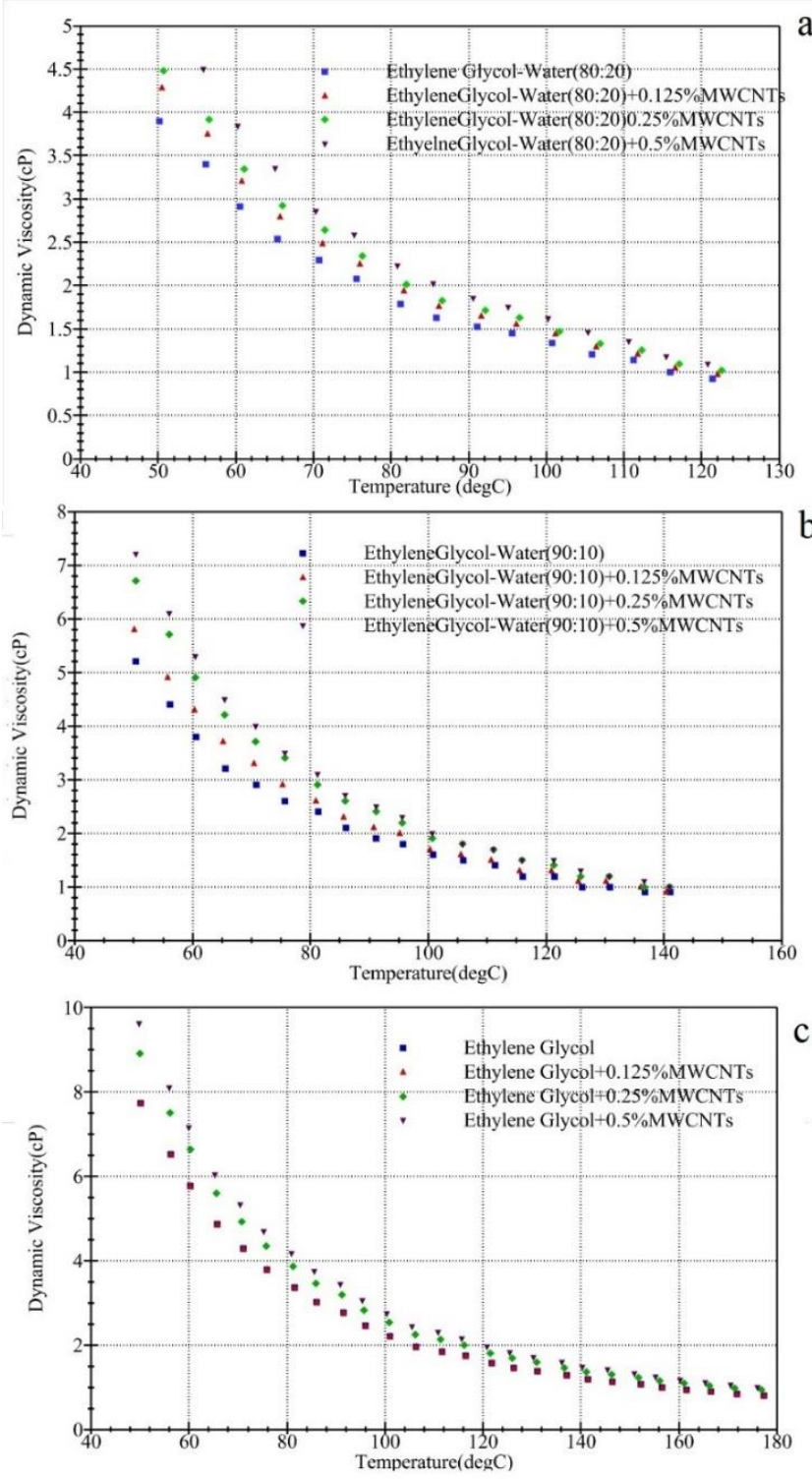

Figure 8. Variation of Dynamic Viscosity with temperature for different Ethylene glycol -water mixture concentrations

\subsection{Regression analysis}

The data is taken to a statistical tool, and regression of experimental data points is done with dependent variables as temperature, percentage of ethylene glycol and the concentration of the MWCNTs. The experimental values of thermal conductivity and dynamic viscosity were separately examined to develop the property assessment regression equations. The equations developed are as shown in Eqns. (1) and (2).

$$
\begin{aligned}
& \frac{k_{n f}}{k_{b}^{0.75}}=1.25\left[1+\frac{T}{T_{\max }}\right]^{-0.18}(1+\emptyset)^{0.4}(1 \\
& \left.+\frac{\alpha}{100}\right)^{-0.7} \\
& \frac{\mu_{n f}}{\mu_{b}^{0.9}}=1.303\left[1+\frac{T}{T_{\max }}\right]^{-0.7}(1+\emptyset)^{0.7}(1 \\
& \left.+\frac{\alpha}{100}\right)^{0.25}
\end{aligned}
$$

The equations could forecast the thermal conductivity and viscosity of Ethylene glycol - water based solar thermic fluids in volume percentage from 80 to $100 \%$ and MWCNTs weight percentage between 0.125 to $0.5 \%$.

\subsection{Validation of experimental values predicted from correlations}

Figure 9 shows the plot with values predicted from equation 1 for thermal conductivity juxtaposed with the experimental data. Figure 10 display the plot with predicted values of correlation equation 2 for dynamic viscosity contrasted with the experimental data. The outcomes revealed that the predicted values of correlation were in good agreement with the experimental data. It can also be found that correlation can forecast both the thermal conductivity and viscosity of nanofluids.

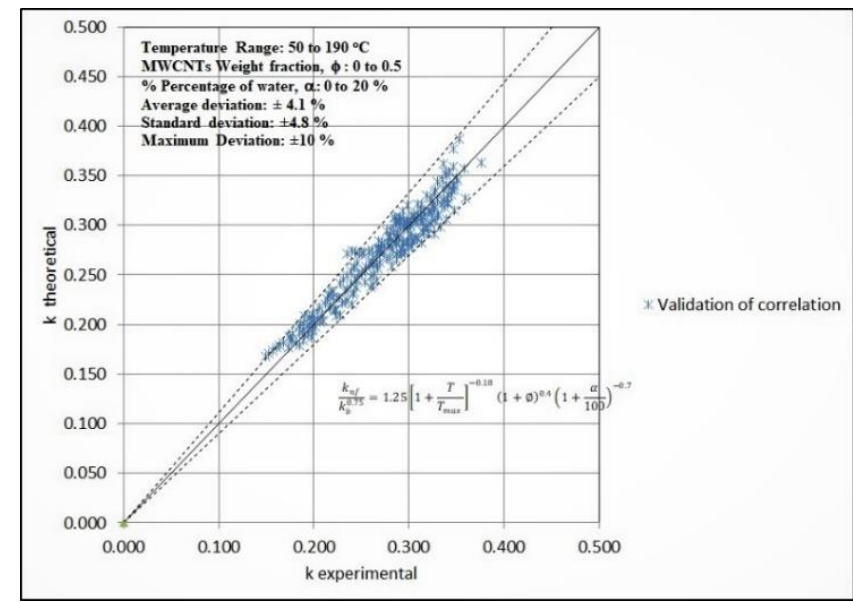

Figure 9. Validation of correlation equation developed for predicting thermal conductivity

Figure 9. depicts the validation of correlation for thermal conductivity proposed in Eq. (1). The proposed Eq. (1) fits the data with an average deviation of $4 \%$ and standard deviation of $4.80 \%$. The equation is in agreement with the current experimental data and within $\pm 10 \%$ deviation. The equation is valid in the range of $0 \leq \varphi \leq 0.5 \%$ and $50 \leq \mathrm{T} \leq 190^{\circ} \mathrm{C}$.

Figure 10 shows the validation of correlation for dynamic viscosity proposed in Eq. (2) and could fit the data with an average deviation of $5.1 \%$ and standard deviation of $6.3 \%$ and all experimental data is within $\pm 11 \%$ deviation. The Eq. (2) is valid in the range of $0 \leq \varphi \leq 0.5 \%$ and $50 \leq \mathrm{T} \leq 150^{\circ} \mathrm{C}$. 


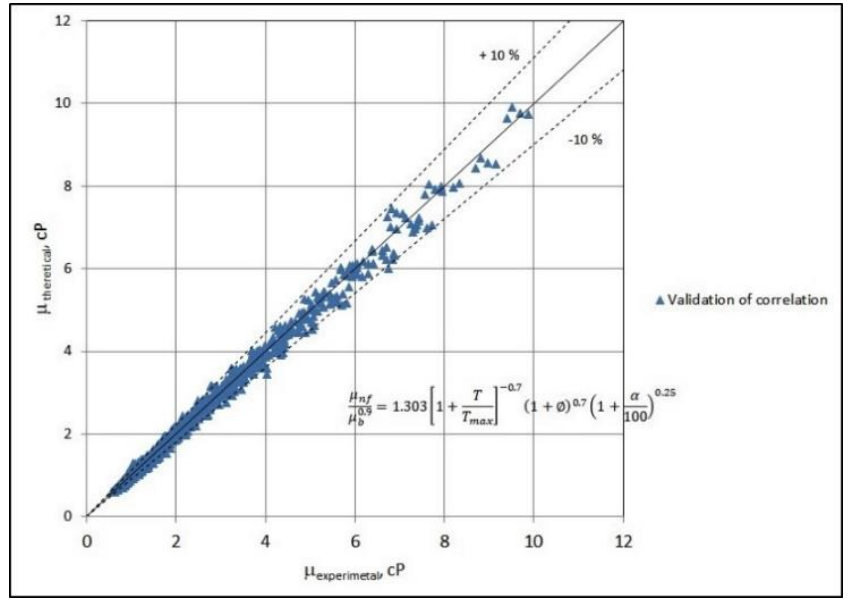

Figure 10. Validation of correlation equation developed for predicting dynamic viscosity

\section{CONCLUSIONS}

The following conclusions can be made from the study.

1 The functionalization of MWCNTs could graft carboxyl and carbonyl groups on their surface, which makes them stable in Ethylene glycol-water mixtures for longer periods compared to pristine MWCNTs.

2 The zeta potential analysis of nanofluids revealed that oxidized MWCNTs could remain stable in Ethylene glycol-water mixtures compared to pristine MWCNTs.

3 Dispersion of oxidized MWCNTs improved the thermal conductivity in the range of 10 to $20 \%$ for all the Ethylene glycol -water ratios.

4 The influence of the surface modification technique on thermal conductivity enhancement is found to be significant. The thermal conductivity enhancement of nanofluids dispersed with oxidized MWCNTs is very high compared to nanofluids dispersed with surfactant-assisted MWCNTs.

5 Nanofluids' dynamic viscosity is found to be higher compared to base fluids in the temperature range of 50 to $70^{\circ} \mathrm{C}$. Nevertheless, at higher temperature ranges, there is minimal variation in viscosity of base and nanofluids.

6 A comprehensive correlation for thermal conductivity and viscosity has been developed which could predict in all temperature and weight fraction ranges.

\section{ACKNOWLEDGMENT}

The authors gratefully acknowledge the support from Hindustan Petroleum Corporation Ltd, the authors also acknowledge the support provided by GITAM (Deemed to be University) in the studies.

\section{REFERENCES}

[1] Chen, X.H., Chen, C.S., Chen, Q., Cheng, F.Q., Zhang, G., Chen, Z.Z. (2002). Non-destructive purification of multi-walled carbon nanotubes produced by catalyzed
CVD. Materials Letters, 57(3): 734-738. https://doi.org/10.1016/S0167-577X(02)00863-7

[2] Das, S.K., Choi, S.U., Patel, H.E. (2006). Heat transfer in nanofluids-A review. Heat Transfer Engineering, 27(10): 3-19. https://doi.org/10.1080/01457630600904593

[3] Hou, P.X., Bai, S., Yang, Q.H., Liu, C., Cheng, H.M. (2002). Multi-step purification of carbon nanotubes. Carbon, 40(1): 81-85. https://doi.org/10.1016/S00086223(01)00075-6

[4] Rosca, I.D., Watari, F., Uo, M., Akasaka, T. (2005). Oxidation of multiwalled carbon nanotubes by nitric acid. Carbon, 43(15): 3124-3131. https://doi.org/10.1016/j.carbon.2005.06.019

[5] Vaisman, L., Wagner, H.D., Marom, G. (2006). The role of surfactants in dispersion of carbon nanotubes. Advances in Colloid and Interface Science, 128-130: 3746. https://doi.org/10.1016/j.cis.2006.11.007

[6] Chiang, Y.C., Lin, W.H., Chang, Y.C. (2011). The influence of treatment duration on multi-walled carbon nanotubes functionalized by $\mathrm{H}_{2} \mathrm{SO}_{4} / \mathrm{HNO}_{3}$ oxidation. Applied Surface Science, 257(6): 2401-2410. https://doi.org/10.1016/j.apsusc.2010.09.110

[7] Chen, H., Ding, Y., He, Y., Tan, C. (2007). Rheological behaviour of ethylene glycol based titania nanofluids. Chemical Physics Letters, 444(4-6): 333-337. https://doi.org/10.1016/j.cplett.2007.07.046

[8] Zhang, X., Gu, H., Fujii, M. (2006). Experimental study on the effective thermal conductivity and thermal diffusivity of nanofluids. International Journal of Thermophysics, 27(2): 569-580. https://doi.org/10.1007/s10765-006-0054-1

[9] Pak, B.C., Cho, Y.I. (1998). Hydrodynamic and heat transfer study of dispersed fluids with submicron metallic oxide particles. Experimental Heat Transfer an International Journal, 11(2): 151-170. https://doi.org/10.1080/08916159808946559

[10] Lee, G.J., Kim, C.K., Lee, M.K., Rhee, C.K. (2011). Characterization of ethylene glycol based Tio. Rev. Adv. Mater. Sci, 28: 126-129.

[11] Duangthongsuk, W. Wongwises, S. (2009). Measurement of temperature-dependent thermal conductivity and viscosity of $\mathrm{TiO}_{2}$-water nanofluids, Exp. Therm. Fluid Sci. 33(4): 706-714.

[12] Cabaleiro, D., Nimo, J., Pastoriza-Gallego, M.J., Piñeiro, M.M., Legido, J.L., Lugo, L. (2015). Thermal conductivity of dry anatase and rutile nano-powders and ethylene and propylene glycol-based $\mathrm{TiO}_{2}$ nanofluids. The Journal of Chemical Thermodynamics, 83: 67-76. https://doi.org/10.1016/j.jct.2014.12.001

[13] Sundar, L.S., Ramana, E.V., Singh, M.K., Sousa, A.C. (2014). Thermal conductivity and viscosity of stabilized ethylene glycol and water mixture $\mathrm{Al}_{2} \mathrm{O}_{3}$ nanofluids for heat transfer applications: An experimental study. International Communications in Heat and Mass Transfer, 56: 86-95. https://doi.org/10.1016/j.icheatmasstransfer.2014.06.00 9

[14] Murshed, S.M.S., Leong, K.C., Yang, C. (2008). Investigations of thermal conductivity and viscosity of nanofluids. International Journal of Thermal Sciences, 47(5): $560-568$. https://doi.org/10.1016/j.ijthermalsci.2007.05.004

[15] Xing, M., Yu, J., Wang, R. (2015). Thermo-physical 
properties of water-based single-walled carbon nanotube nanofluid as advanced coolant. Applied Thermal Engineering, 87: 344-351. https://doi.org/10.1016/j.applthermaleng.2015.05.033

[16] Wang, X.J., Li, X., Yang, S. (2009). Influence of $\mathrm{pH}$ and SDBS on the stability and thermal conductivity of nanofluids. Energy \& Fuels, 23(5): 2684-2689. https://doi.org/10.1021/ef800865a

[17] Reddy, M.C.S., Rao, V.V. (2013). Experimental studies on thermal conductivity of blends of ethylene glycolwater-based $\mathrm{TiO}_{2}$ nanofluids. International Communications in Heat and Mass Transfer, 46: 31-36. https://doi.org/10.1016/j.icheatmasstransfer.2013.05.00 9

[18] Vajjha, R.S., Das, D.K., Chukwu, G.A. (2015). An experimental determination of the viscosity of propylene glycol/water based nanofluids and development of new correlations. Journal of Fluids Engineering, 137(8): 081201. https://doi.org/10.1115/1.4029928

[19] Jiang, H., Xu, Q., Huang, C., Shi, L. (2015). The role of interfacial nanolayer in the enhanced thermal conductivity of carbon nanotube-based nanofluids. Applied Physics A, 118(1): 197-205. https://doi.org/10.1007/s00339-014-8902-5

[20] Suganthi, K.S., Rajan, K.S. (2014). A formulation strategy for preparation of $\mathrm{ZnO}$-propylene glycol-water nanofluids with improved transport properties. International Journal of Heat and Mass Transfer, 71: 653-
663.

https://doi.org/10.1016/j.ijheatmasstransfer.2013.12.044

[21] Esfe, M.H., Saedodin, S., Naderi, A., Alirezaie, A., Karimipour, A., Wongwises, S., bin Dahari, M. (2015). Modeling of thermal conductivity of $\mathrm{ZnO}-\mathrm{EG}$ using experimental data and ANN methods. International Communications in Heat and Mass Transfer, 63: 35-40. https://doi.org/10.1016/j.icheatmasstransfer.2015.01.00 1

[22] Baratpour, M., Karimipour, A., Afrand, M., Wongwises, S. (2016). Effects of temperature and concentration on the viscosity of nanofluids made of single-wall carbon nanotubes in ethylene glycol. International Communications in Heat and Mass Transfer, 74: 108-113. https://doi.org/10.1016/j.icheatmasstransfer.2016.02.00 8

[23] Afrand, M., Toghraie, D., Ruhani, B. (2016). Effects of temperature and nanoparticles concentration on rheological behavior of $\mathrm{Fe}_{3} \mathrm{O}_{4}-\mathrm{Ag} / \mathrm{EG}$ hybrid nanofluid: an experimental study. Experimental Thermal and Fluid Science, 77: 38-44. https://doi.org/10.1016/j.expthermflusci.2016.04.007

[24] Shojaeizadeh, E., Veysi, F., Yousefi, T., Davodi, F. (2014). An experimental investigation on the efficiency of a Flat-plate solar collector with binary working fluid: A case study of propylene glycol (PG)-water. Experimental Thermal and Fluid Science, 53: 218-226. https://doi.org/10.1016/j.expthermflusci.2013.12.011 